\title{
Expresión de Citocinas Pro-Inflamatorias de Leucocitos de Alpaca (Vicugna pacos) Inducidos por el Extracto de Macroquistes de Sarcocystis aucheniae
}

\author{
Expression of Pro-inflammatory Citokines of Alpaca (Vicugna PaCos) Leukocytes \\ IndUCED By EXTRACT OF MACroCyst OF SARCoCystis AUCHENIAE
}

\author{
Rocío Hinostroza S. ${ }^{1}$, Alberto Manchego S., ${ }^{1,3}$, Nieves Sandoval C. ${ }^{2}$, \\ Kim-Lam Chiok C. ${ }^{1}$, Juan More B. ${ }^{1}$
}

\section{Resumen}

\begin{abstract}
El objetivo del trabajo fue determinar la expresión de citocinas pro-inflamatorias de leucocitos de alpaca mediante el enfrentamiento antigénico de extracto de macroquistes de Sarcocystis aucheniae a diversas dosis y tiempos de exposición. Se empleó una concentración de leucocitos de 500 000/ml expuestos a 0.5, 1, 50, 500 y $1000 \mathrm{ng}$ de extracto de macroquistes de $S$. aucheniae e incubados por 1, 12 y $24 \mathrm{~h}$. Se extrajo los ARN mensajeros (ARNm) totales de cada tratamiento con Trizol y se utilizaron en una RT-PCR tiempo real con cebadores específicos de la citosina TNF- $\alpha$ e interleucinas IL- $1 \alpha$, IL- $1 \beta$ e IL-6. Se observó que los niveles de ARNm de IL-1 $\alpha$ y TNF- $\alpha$ generados a $1 \mathrm{~h}$ de incubación eran detectables y comparativamente elevados con respecto al calibrador (leucocitos no expuestos a extracto). La IL-1 $\beta$ se encontró incrementada en la concentración de $1 \mathrm{ng} / \mathrm{ml}$ a las 24 h, mostrando una cinética de expresión negativa en comparación con el control no tratado. La IL-6 no se evidenció mediante RT-PCR tiempo real. Asimismo, se realizó la observación de viabilidad leucocitaria a los tiempos de 1, 12 y $24 \mathrm{~h}$ permitiendo corroborar el efecto tóxico del extracto de macroquistes de $S$. aucheniae a altas concentraciones.
\end{abstract}

Palabras clave: Sarcocystis aucheniae, interleucinas, pro-inflamatorias, alpaca

\section{Abstract}

The aim of this research was to determine the expression of proinflammatory cytokines from alpaca leukocytes through the antigenic challenge with macrocyst extract of Sarcocystis aucheniae at various doses and exposure times. Leukocytes in a concentration of 500000 cells $/ \mathrm{ml}$ were exposed to concentrations of $0.5,1,50,500$ and $1000 \mathrm{ng}$ of

\footnotetext{
${ }^{1}$ Laboratorio de Microbiología y Parasitología Veterinaria, ${ }^{2}$ Laboratorio de Histología, Embriología y Patología Veterinaria, Facultad de Medicina Veterinaria, Universidad Nacional Mayor de San Marcos, Lima, Perú

${ }^{3}$ E-mail: amanchegos@gmail.com
}

Recibido: 4 de enero de 2014

Aceptado para publicación: 18 de setiembre de 2014 
macrocyst extract of $S$. aucheniae and incubated for 1, 12 and $24 \mathrm{~h}$. The total messenger RNA (mRNA) was extracted for each treatment using Trizol and used to perform real-time RT-PCR with specific primers for cytokine TNF- $\alpha$ and interleukins IL- $1 \alpha$, IL- $1 \beta$ and IL-6. The generated mRNA levels of IL- $1 \alpha$ and TNF- $\alpha$ at $1 \mathrm{~h}$ were detectable and higher in comparison to the calibrator (leukocytes not exposed to the extract). IL- $1 \beta$ increased at the $1 \mathrm{ng} / \mathrm{ml}$ concentration at $24 \mathrm{~h}$ showing a negative kinetic expression when compared with the untreated control group. IL- 6 was not evidenced by RT-PCR real time. In addition, the leukocytes viability at 1,12 and $24 \mathrm{~h}$ corroborated the toxic effect of the macrocyst extract of $S$. aucheniae at high concentrations.

Key words: Sarcocystis aucheniae, interleukins, pro-inflammatory, alpaca

\section{INTRODUCCIÓN}

Las alpacas son animales emblemáticos del Perú, siendo su crianza un soporte económico del poblador alto-andino. Las enfermedades infecciosas, tanto bacterianas como parasitarias, son un freno para el desarrollo de la ganadería alpaquera, dado que causan disminución de la eficiencia productiva, pérdida de calidad de la fibra, decomiso de la carne y muerte de los animales (Moro, 1987).

Una de las parasitosis más prevalentes en las alpacas y llamas del país es la sarcocystiosis, la que ocasiona merma en la calidad de la carne, además de limitar su venta y consumo. La mayor parte de la población de camélidos adultos se encuentra infectado, con seroprevalencias de $89.7 \%$ (Castro et al., 2004), debido al estrecho contacto con los perros pastores, pues el perro es el hospedero definitivo más importante en este tipo de crianza (Choque et al., 2007); sin embargo, poco se conoce sobre los mecanismos de infección parasitaria por Sarcocystis aucheniae, la forma de estimulación del sistema inmune y el mecanismo de reconocimiento de sus antígenos (Leguía, 1991).

Los extractos de macroquistes de $S$. aucheniae han demostrado contener proteínas con poder tóxico, como la sarcocystina, que produce alteraciones de distinta severidad en el tejido digestivo y nervioso, cuando los quistes son ingeridos. Asimismo, la susceptibilidad y resistencia a estas toxinas varía entre especies (Sam et al., 1998). La Perle et al. (1999) demostraron la presencia de miositis eosinofílica en los hospederos intermediarios, mientras que otros autores señalan una adaptación al parásito sin lesiones físicas evidentes, pero con buena respuesta inmune (Uggla y Boxton, 1990).

El presente trabajo estuvo enfocado a determinar si existe una respuesta inicial (proinflamatoria) de los leucocitos de alpaca al enfrentamiento antigénico de extracto de macroquistes de $S$. aucheniae teniendo en consideración el tiempo de exposición. Para esto, se detectó la expresión de de interleucinas pro-inflamatorias de leucocitos circulantes.

\section{Materiales y Métodos}

\section{Animales y Muestras}

Para la obtención de leucocitos, se recolectó $7 \mathrm{ml}$ de sangre entera por venopunción de cinco alpacas (3 hembras y 2 machos) de dos años de edad, procedentes de un rebaño de alpacas del IVITA Maranganí, Cusco, Perú. Se utilizaron vacutainers conteniendo EDTA. Todos los animales fueron negativos a la presencia de anticuerpos contra $S$. aucheniae en la prueba de ELISA. 
Los macroquistes de $S$. aucheniae se recolectaron de la musculatura cervical de cinco alpacas naturalmente infectadas, que fueron sacrificadas en el camal municipal de la ciudad de Huancavelica. Se utilizó material estéril. Los quistes recolectados conservaban sus respectivas envolturas quísticas y estaban libres de fibras musculares. Las muestras fueron colocadas en suero salino tamponado (PBS) para evitar la deshidratación.

\section{Extracción de Antígenos de Macroquis- tes}

Los macroquistes fueron molidos en un mortero frío conteniendo $5 \mathrm{ml}$ de PBS hasta obtener una pasta homogénea. Luego se centrifugó por $10 \mathrm{~min}$ a $1200 \mathrm{~g}$ y a $4^{\circ} \mathrm{C}$. El pellet resultante fue re-suspendido en Medio Mínimo Esencial (MEM) en la proporción de 1 en 2 y la suspensión fue sometida a ultrasonido utilizando el sonicador Fisher-300 (Thermo Fisher Scientific) por 60 ciclos/s en intervalos de $60 \mathrm{~s}$. La destrucción de las membranas celulares fue verificada al microscopio. Los productos sonicados fueron centrifugados a $3000 \mathrm{~g}$ por $20 \mathrm{~min}$, siguiendo el protocolo descrito por Sam et al. (1998). El sobrenadante y el pellet se almacenaron por separado a $-20{ }^{\circ} \mathrm{C}$.

La concentración de proteínas totales (antígenos totales) del extracto obtenido del pellet fue medido mediante el Qubit ${ }^{\circledR} 2.0$ Quantitation Starter Kit (Invitrogen, California, EEUU), empleando el reactivo designado para proteínas y siguiendo las instrucciones del fabricante. La concentración de antígeno total fue ajustada para los tratamientos empleados mediante dilución en MEM libre de antibióticos.

\section{Obtención de Leucocitos}

La sangre fresca de las alpacas se centrifugó en forma inmediata a la colecta, a $700 \mathrm{~g}$ por $10 \mathrm{~min}$. La capa flogística fue separada en crioviales de $2 \mathrm{ml}$. Los glóbulos rojos de la capa flogística se retiraron agregando PBS $0.15 \mathrm{M}$ pH 7.2 y centrifugando a $2500 \mathrm{rpm}$ por $5 \mathrm{~min}$. Se eliminó el sobrenadante y se agregó 5 volúmenes de Tris $0.01 \mathrm{M}$ - cloruro de amonio $0.85 \%$ frío, se homogenizó e incubó a $4{ }^{\circ} \mathrm{C}$ durante $1 \mathrm{~h}$. Luego, se centrifugó a $1200 \mathrm{~g}$ por $10 \mathrm{~min}$ y se eliminó el sobrenadante. Los leucocitos se lavaron tres veces con PBS de manera similar a lo descrito para eliminar restos de cloruro de amonio y se re-suspendieron en MEM libre de antibióticos.

\section{Procedimiento}

\section{Estimulación de leucocitos}

Para determinar la calidad y viabilidad de los leucocitos purificados, se empleó el colorante vital azul de tripán al $0.3 \%$ en proporción 1:2 con los leucocitos re-suspendidos en MEM. Las células vivas (brillantes y no teñidas de azul) se contaron en la cámara de Newbauer con microscopio óptico a 400x. El cálculo del número de células vivas totales de la suspensión se calculó con la siguiente fórmula (Darling y Morgan, 1993): Número de leucocitos $/ \mathrm{ml}=$ Promedio de la sumatoria de los 4 cuadrantes x 2 × 10000 .

Las suspensiones fueron diluidas para obtener 500000 leucocitos vivos/ml de MEM. Se colocó $1 \mathrm{ml}$ de suspensión de leucocitos en cada pocillo de microplaca de 12 pocillos. Los tratamientos experimentales consistieron en el enfrentamiento de esta dosis de leucocitos vivos a concentraciones crecientes de antígeno total de macroquistes de $S$. aucheniae $(0.5,1,50,500$ y $1000 \mathrm{ng} / \mathrm{ml})$, cada una por triplicado (tres pocillos por dosis), por periodos de 1,12 y $24 \mathrm{~h}$. Adicionalmente, y por cada tratamiento, se agregó un control de leucocitos $(500$ 000/ml) inoculados con suero fisiológico, que sirvió de calibrador en la prueba de PCR tiempo real, para evaluar las variaciones normales de la expresión de las interleucinas. Los tratamientos tuvieron tres repeticiones. 
Cuadro 1. Oligonucleótidos y temperatura de hibridación para RT-PCR Tiempo Real para la detección de las interleucinas 1,6 y TNF- $\alpha$

\begin{tabular}{|c|c|c|c|c|}
\hline Citocina & $\begin{array}{l}\text { Tamaño } \\
(\mathrm{pb})^{1}\end{array}$ & Oligonucleótidos & $\mathrm{Ta}\left({ }^{\circ} \mathrm{C}\right)^{2}$ & Referencia \\
\hline $\begin{array}{l}\text { IL } 1 \alpha \mathrm{F}\left(5^{\prime}\right) \\
\mathrm{IL} 1 \alpha \mathrm{R}\left(3^{\prime}\right)\end{array}$ & 172 & $\begin{array}{l}\text { GATGCCTGAGACACCCAA } \\
\text { GAAAGTCAGTGATCGAGGG }\end{array}$ & 53 & $\begin{array}{l}\text { Odbileg et } \\
\text { al. (2005) }\end{array}$ \\
\hline $\begin{array}{l}\text { IL } 1 \beta F\left(5^{\prime}\right) \\
\text { IL } 1 \beta R\left(3^{\prime}\right)\end{array}$ & 259 & $\begin{array}{l}\text { AAGTGGTGTTCTGCATGAGC } \\
\text { TGACAAGTGCTGATGTACCA }\end{array}$ & 53 & $\begin{array}{l}\text { Odbileg et } \\
\text { al. (2005) }\end{array}$ \\
\hline $\begin{array}{l}\left.\text { IL } 6 \text { F( } 5^{\prime}\right) \\
\text { IL } 6 \text { R( }\left(3^{\prime}\right)\end{array}$ & 193 & $\begin{array}{l}\text { CTCTGCAATGAGAAAGGAGA } \\
\text { GGTAGTCCAGGTATATCTGA }\end{array}$ & 51 & $\begin{array}{l}\text { Odbileg et } \\
\text { al. (2005) }\end{array}$ \\
\hline $\begin{array}{l}\text { TNF } \alpha \mathrm{F}\left(5^{\prime}\right) \\
\mathrm{TNF} \alpha \mathrm{R}\left(3^{\prime}\right)\end{array}$ & 251 & $\begin{array}{l}\text { CTACTCCCAGGTCCTCCTGA } \\
\text { GGTAGTTGGGCATGTTGATC }\end{array}$ & 56 & $\begin{array}{l}\text { Odbileg et } \\
\text { al. (2005) }\end{array}$ \\
\hline $\begin{array}{l}\text { GAPDH F (5') } \\
\text { GAPDH R (3') }\end{array}$ & 356 & $\begin{array}{l}\text { GTGAAGGTCGGAGTGAACG } \\
\text { GAGATGATGACCCTCTTGGC }\end{array}$ & 60 & $\begin{array}{l}\text { Patil et al. } \\
\text { (2004) }\end{array}$ \\
\hline
\end{tabular}

Los enfrentamientos se realizaron en placas de cultivo descartables y bajo incubación a $37{ }^{\circ} \mathrm{C}$ con $5 \%$ de $\mathrm{CO}_{2}$. Al final de cada tratamiento, los leucocitos fueron recuperados en crioviales de $1.5 \mathrm{ml} \mathrm{y}$ centrifugados a $1200 \mathrm{~g}$ por $10 \mathrm{~min}$. El sobrenadante fue retirado y las células fueron congeladas a $-35{ }^{\circ} \mathrm{C}$ hasta su uso en la extracción de ARN total.

\section{Extracción de ARN celular}

En la evaluación de la expresión de interleucinas IL- $1 \alpha$, IL- $1 \beta$, IL-6 y TNF- $\alpha$, las muestras se procesaron con TRIzol ${ }^{\circledR}$ Reagent (Invitrogen, EEUU) para la obtención de los ARN totales, siguiendo las instrucciones del fabricante.

Sintesis de cADN

Para la Transcripción Reversa (RT) se utilizó el kit SuperScript ${ }^{\mathrm{TM}}$ III Platinum ${ }^{\circledR}$ SYBR ${ }^{\circledR}$ Green Two-Step qRT-PCR Kit with ROX (Invitrogen, EEUU), de acuerdo a las instrucciones del fabricante. Se colocó $18 \mu 1$ del master mix en tubos para termociclador en tiempo real y se adicionaron $2 \mu 1$ de muestra $(0.5 \mu \mathrm{g}$ de ARN total), para obtener un volumen de reacción de $20 \mu 1$. Las muestras fueron llevadas al termociclador PTC 200 Chromo 4 (detector continuo de fluorescencia) de MJ Research, incubándose a $25{ }^{\circ} \mathrm{C}$ por $10 \mathrm{~min}, 37^{\circ} \mathrm{C}$ por $20 \mathrm{~min}$ y $85^{\circ} \mathrm{C}$ por $5 \mathrm{~min}$ para terminar la reacción. El producto obtenido fue congelado a $-70{ }^{\circ} \mathrm{C}$ hasta su uso en el PCR.

\section{PCR Tiempo Real}

El PCR en tiempo real se hizo en un termociclador equipado con un monitor de detección de fluorescencia continua (MJ Research, BioRad), usando el agente intercalante SYBR Green. Para esto se utilizó el ADN complementario (ADNc) de los ARN totales obtenidos en el paso anterior (RT). Asimismo, se emplearon los oligonucleótidos específicos de llama descritos por Odbileg et al (2005) indicados en el Cuadro 1. 
Para la reacción en tiempo real se empleó el kit SuperScript ${ }^{\mathrm{TM}}$ III Platinum ${ }^{\circledR}$ SYBR ${ }^{\circledR}$ Green Two-Step qRT-PCR Kit with ROX (Invitrogen, EEUU), de acuerdo a las instrucciones del fabricante. Se utilizó el termociclador mencionado anteriormente, empleándose protocolos de acuerdo a la temperatura de disociación de cada juego de oligonucleótidos (Odbileg et al., 2005).

Como control endógeno, se evaluó la producción del ARNm del gen constitutivo GAPDH, necesario para la técnica cuantitativa y la evaluación de la técnica molecular. Se empleó el protocolo: $50^{\circ} \mathrm{C}$ por $2 \mathrm{~min}$ (incubación con UDG), $95{ }^{\circ} \mathrm{C}$ por $10 \mathrm{~min}$ (inactivación UDG y activación de DNA polimerasa), seguido de 40 ciclos de $95{ }^{\circ} \mathrm{C}$ por $15 \mathrm{~s} \mathrm{y} 60^{\circ} \mathrm{C}$ por $1 \mathrm{~min}$. La mezcla de reacción contiene UDG, $\mathrm{MgCl}_{2}$ y dNTPs que incluye al dUTP, estableciendo un sistema tampón y estabilizadores, asegurando que cualquier amplificado de ADN contiene uracilos, mientras que UDG elimina los residuos de uracilo del ADN de una o doble cadena degradando al ADN formado e impidiendo que el ADN que contiene dUTP sirva como plantilla de PCRs futuros.

Para determinar la producción de los ARNm de las citocinas IL- $1 \alpha$, IL- $1 \alpha \beta$, IL-6 y TNF- $\alpha$ se empleó el siguiente protocolo: $50{ }^{\circ} \mathrm{C}$ por $2 \mathrm{~min}$ (incubación con UDG), $95^{\circ} \mathrm{C}$ por 10 min (inactivación UDG y activación de DNA polimerasa), seguido de 40 ciclos de $94{ }^{\circ} \mathrm{C}$ por $30 \mathrm{~s}$, temperatura de hibridación (Ta en ${ }^{\circ} \mathrm{C}$ ), según cada juego de oligonucleótidos (ver Cuadro 1 ) por $30 \mathrm{~s} \mathrm{y} 72{ }^{\circ} \mathrm{C}$ por $30 \mathrm{~s}$.

Los resultados fueron evaluados a través del software Opticon Monitor v. 2.1, obteniéndose los valores de $\mathrm{Ct}$ (Cycle threshold o ciclo umbral) para su uso en el análisis $2^{-\Delta \Delta C t}$ como método de cuantificación relativa y el valor de Tm (Temperatura de «melting» o disociación) de cada uno de los productos para evaluar la especificidad de los productos amplificados. Se hicieron tres repeticiones por tratamiento y por cada interleucina evaluada para obtener los promedios de $\mathrm{Ct}$ y $\mathrm{Tm}$ de cada tratamiento.

\section{Cuantificación relativa de los productos de RT-PCR Tiempo Real (citocinas)}

La cuantificación relativa de los resultados de las interleucinas se realizó con el método $2^{-\mathrm{Ä} A ̈ C t} \mathrm{o}$ método $\mathrm{Ct}$ comparativo (Livak y Schmittgen, 2001; Pfaffl, 2001; Rebrikov y Trofimov, 2006), basado en el análisis de los $\mathrm{Ct}$ de las muestras comparados con el $\mathrm{Ct}$ de un control endógeno $(\mathrm{GAPDH})$ en relación a una muestra calibrador: $\mathrm{N}=2^{-\Delta \Delta \mathrm{Ct}}$, donde $\mathrm{N}=$ Cantidad relativa de ARNm con respecto al calibrador; y $\Delta \Delta \mathrm{Ct}=$ Diferencia entre el control endógeno y el ARNm a analizar con respecto al calibrador.

Los resultados son presentados como cantidades en número de veces con respecto a un calibrador. Se empleó un calibrador para cada periodo de tiempo evaluado, existiendo tres calibradores que consistieron de leucocitos control incubados por 1, 12 y $24 \mathrm{~h}$. Bajo este esquema, se compararon los niveles de expresión de ARNm de las interleucinas bajo distintas concentraciones de dosis de antígeno completo en un mismo periodo de tiempo. Igualmente, se compararon los niveles de expresión bajo la misma concentración de antígeno completo, pero en diferentes periodos de tiempo para evaluar el cambio de expresión a través del tiempo; tomándose como calibrador, leucocitos control a 1 $\mathrm{h}$ de incubación como nivel basal de expresión.

Electroforesis de los productos de RT-PCR

Para el análisis de los productos del RTPCR de interleucinas IL-1 $\alpha$, IL-1 $\beta$, IL-6 y TNF- $\alpha$ se empleó la técnica de electroforesis en geles agarosa al $2 \%$ en buffer TBE $1 x$. Se tomaron $20 \mu 1$ de los productos de PCR y se adicionaron $4 \mu \mathrm{l}$ de buffer de carga $6 \mathrm{x}$ en cada muestra, cargándose la mezcla en los carriles del gel. Un carril fue utilizado para el marcador de peso molecular Novagen Perfect DNA Ladder (Novagen, EEUU). 
Cuadro 2. Detección de ARNm de citocinas pro-inflamatorias en leucocitos de alpacas expuestas a extracto de macroquistes de Sarcocystis aucheniae

\begin{tabular}{cccc}
\hline Citocina & $\begin{array}{c}\text { Tamaño del producto } \\
(\mathrm{pb})\end{array}$ & $\mathrm{Ct}$ & $\mathrm{Tm}\left({ }^{\circ} \mathrm{C}\right)$ \\
\hline IL-1 $\alpha$ & 172 & $27.86-36.00$ & $79.1-79.4$ \\
IL-1 $\beta$ & 259 & $33.57-37.69$ & $79.4-80.9$ \\
TNF- $\alpha$ & 251 & $26.01-35.19$ & $85.1-86.0$ \\
IL-6 & No detectado & No detectado & No detectado \\
\hline
\end{tabular}

La electroforesis se realizó a $100 \mathrm{~V}$ por $1 \mathrm{~h}$ en una cámara de electroforesis horizontal (Biorad, EEUU). Luego, las bandas de $\mathrm{ADN}$ teñidas con bromuro de etidio fueron visualizadas en un transiluminador UV.

\section{Análisis Estadístico}

Se calcularon los valores promedio $2^{-\Delta \Delta \mathrm{Ct}}$ por cada tratamiento y tiempo. Se utilizó el análisis de varianza para determinar si existe diferencia estadística entre tratamientos por cada periodo y entre periodos de un mismo tratamiento. Se empleó el software Stata SE v. 10.1.

Además, se determinó la correlación existente entre la concentración de antígeno completo de $S$. aucheniae y los niveles de expresión de ARNm de cada interleucina evaluadas bajo un mismo periodo.

\section{Resultados}

\section{RT-PCR Tiempo Real del ARNm de GAPDH}

Todos los tratamientos mostraron la presencia de ARNm de GAPDH, tanto en gel de electroforesis (Fig. 1) como en los resultados de PCR en tiempo real (Fig. 2). Se amplificó un producto único y específico con
Tm de $80.9 \pm 0.3$ o $83.3 \pm 0.3{ }^{\circ} \mathrm{C}$ (Fig. 2), con correspondencia total con los productos de $356 \mathrm{pb}$ observados en los geles de agarosa al $2 \%$ descritos por Patil et al. (2004), e indicando la viabilidad de los leucocitos durante el periodo de evaluación. Los promedios de $\mathrm{Ct}$ de cada tratamiento y controles fueron empleados en la técnica de cuantificación relativa $2^{-\Delta \Delta \mathrm{Ct}}$.

\section{RT-PCR en Tiempo Real del ARNm de IL-1 $\alpha$, IL-1 $\beta$, IL-6 y TNF- $\alpha$}

Las pruebas de RT-PCR para amplificar las regiones escogidas de los mRNA de la IL- $1 \alpha$, IL1- $\beta$, IL-6 y TNF- $\alpha$ evidenciaron un producto específico en los geles de agarosa al 2\% del tamaño esperado (Cuadro 2); asimismo, los valores de $\mathrm{Ct}$ y Tm de cada ensayo para determinar las citocinas se muestran en ese cuadro. Cabe destacar que no se detectó ARNm de la IL-6.

\section{Cuantificación Relativa de las Interleucinas según la Dosis de Antígeno}

Las expresiones de la IL-1 $\alpha$ a distintas concentraciones del extracto y a distintas horas se presentan en la Fig. 3. La IL-1 $\alpha$ se expresa en sus niveles máximos a una menor concentración de extracto $(0.5 \mathrm{ng} / \mathrm{ml})$ y a una hora de incubación, siendo 47.85 veces lo expresado en el calibrador (células no trata- 


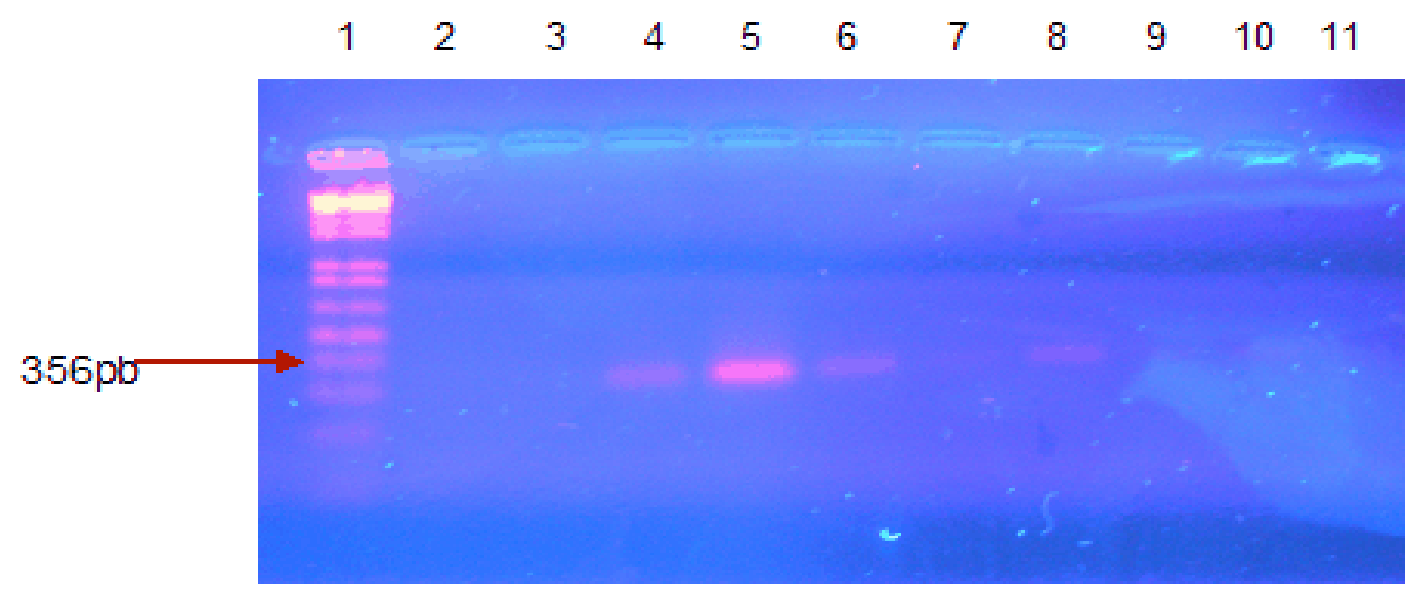

Figura 1. Electroforesis en gel de agarosa al 2\% de los productos del RT-PCR de GAPDH. 1: Novagen Perfect DNA 50 bp ladder; 2 y 3: vacío; 4: suero fisiológico x 24 h; 5: $0.5 \mathrm{ng}$ x 1 h; 6: 1 ng x 1 h; 7: 50 ng x 1 h; 8: 500 ng x 1 h; 9: 1000 ng x 1 h; 10 y 11: vacío

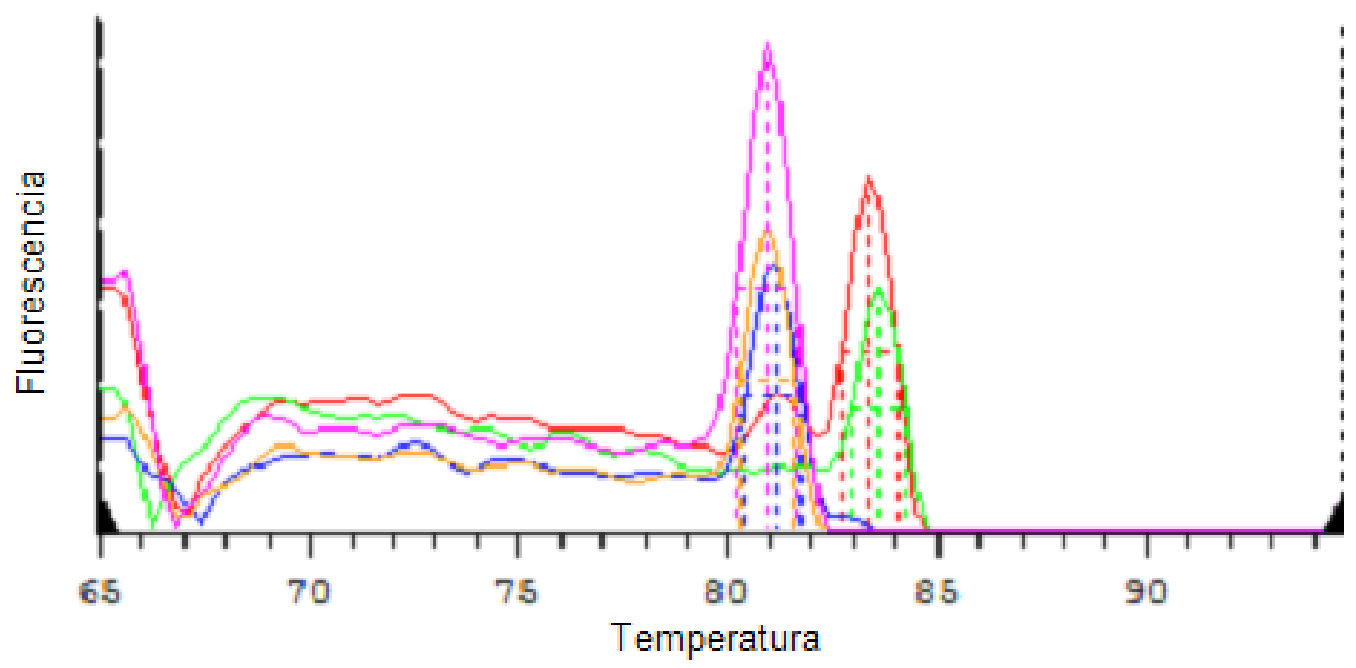

Figura 2. Análisis de temperatura de disociación de los productos de RT-PCR Tiempo Real empleando oligonucleótidos GAPDH. Fucsia, naranja y azul $\mathrm{Tm}=80.9 \pm 0.3{ }^{\circ} \mathrm{C}$; Rojo $\mathrm{Tm}=83.3{ }^{\circ} \mathrm{C}$; Verde $\mathrm{Tm}=83.6^{\circ} \mathrm{C}$.

das). La expresión disminuye con el aumento de concentración y con el tiempo de incubación $(p<0.05)$, siendo sus coeficientes de correlación negativos en todos los casos, llegando a detectarse expresiones de la IL$1 \alpha$ menores a las de las celulas no tratadas.
El análisis para expresión de IL-1 $\beta$ exhibe un patrón distinto al mostrado por IL-1 $\alpha$ (Fig. 4). La máxima expresión relativa (37.95 veces) se presentó a las $24 \mathrm{~h}$ de incubación con $1 \mathrm{ng} / \mathrm{ml}$ de extracto de macroquiste $(p<0.05)$. Independientemente de la con- 


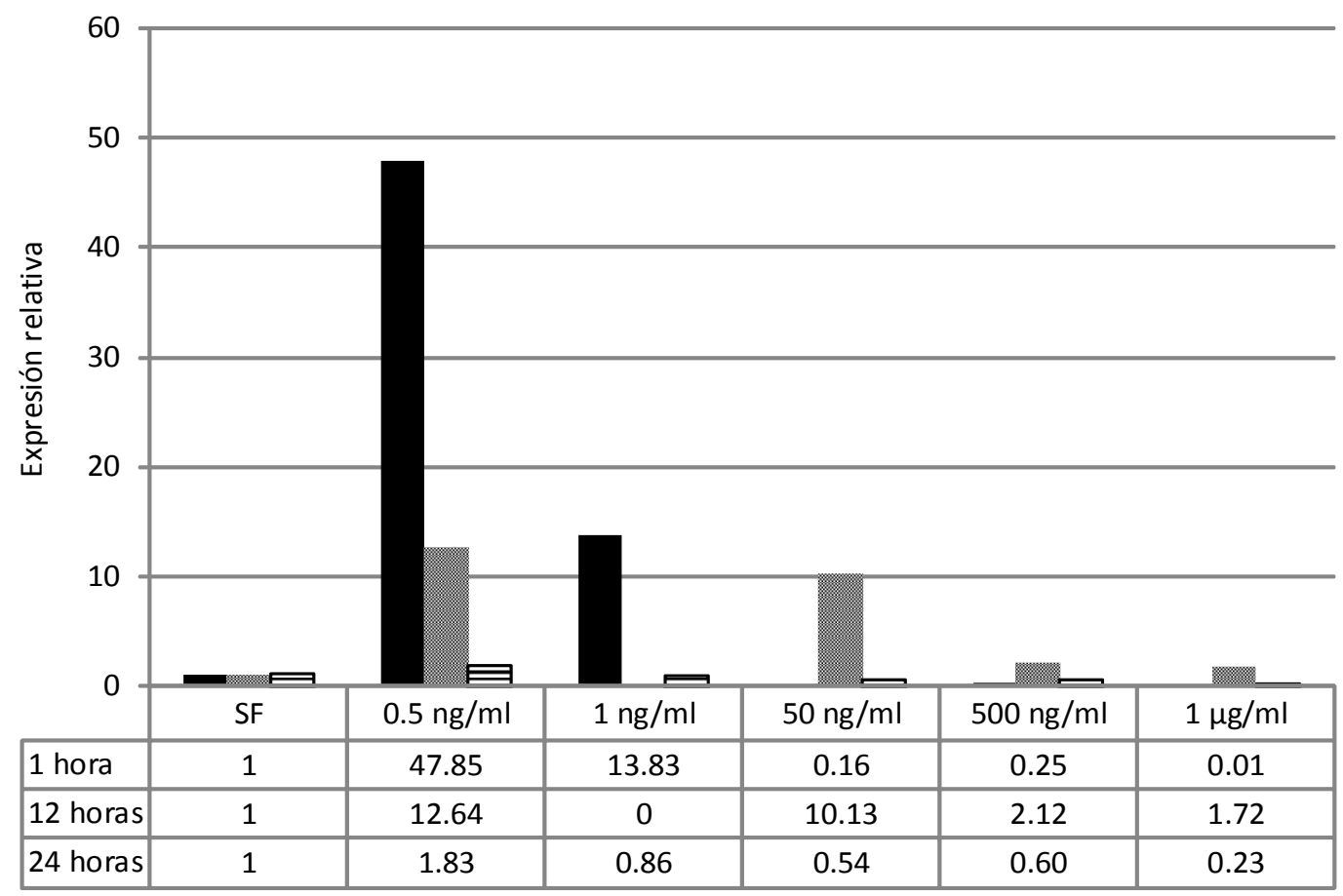

Figura 3. Expresión relativa de ARNm de IL-1 $\alpha$ según la concentración del extracto de macroquistes de $S$. aucheniae y el tiempo de incubación $(*=\mathrm{p}<0.05)$

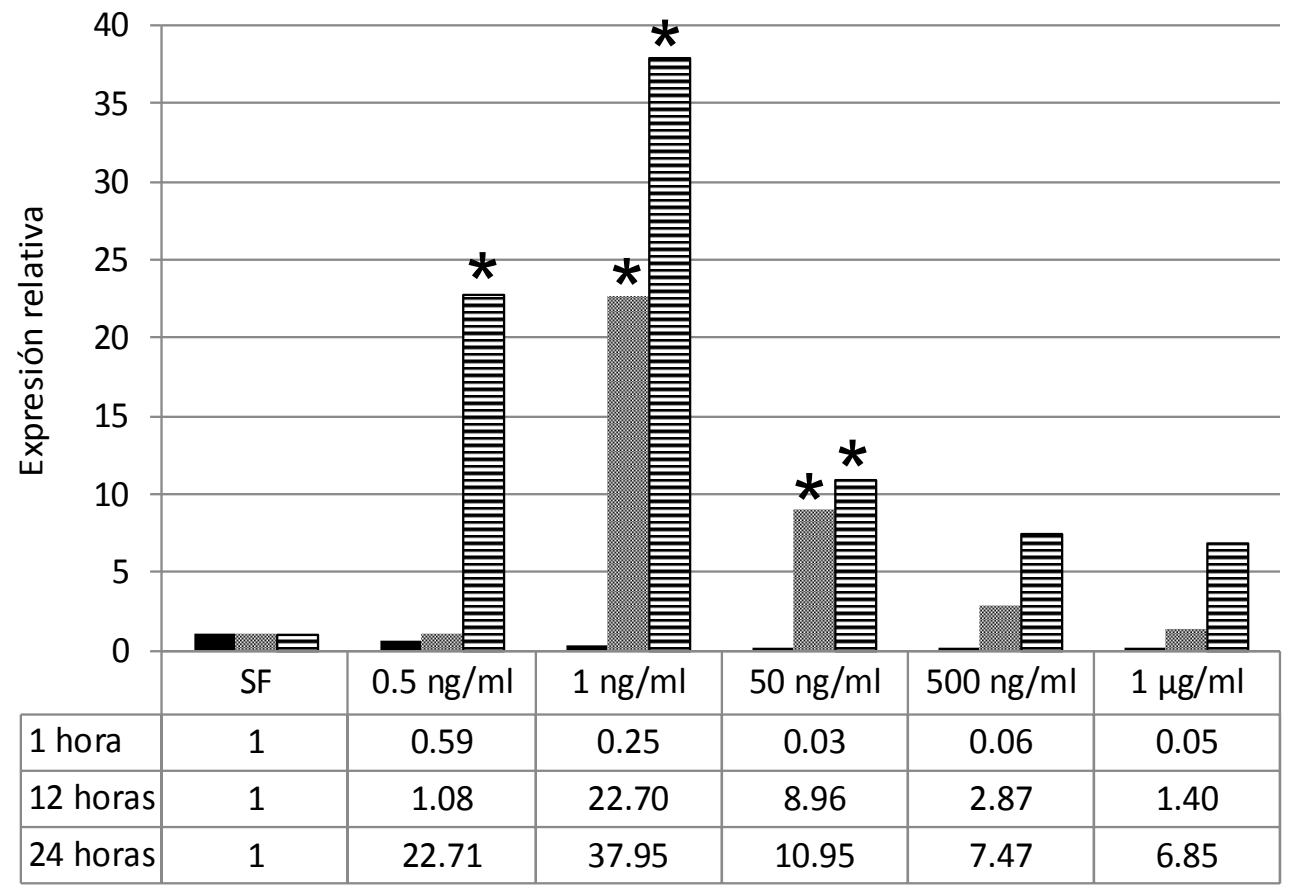

Figura 4. Expresión relativa de ARNm de IL-1 $\beta$ según la concentración del extracto de macroquistes de $S$. aucheniae y el tiempo de incubación $(*=\mathrm{p}<0.05)$ 


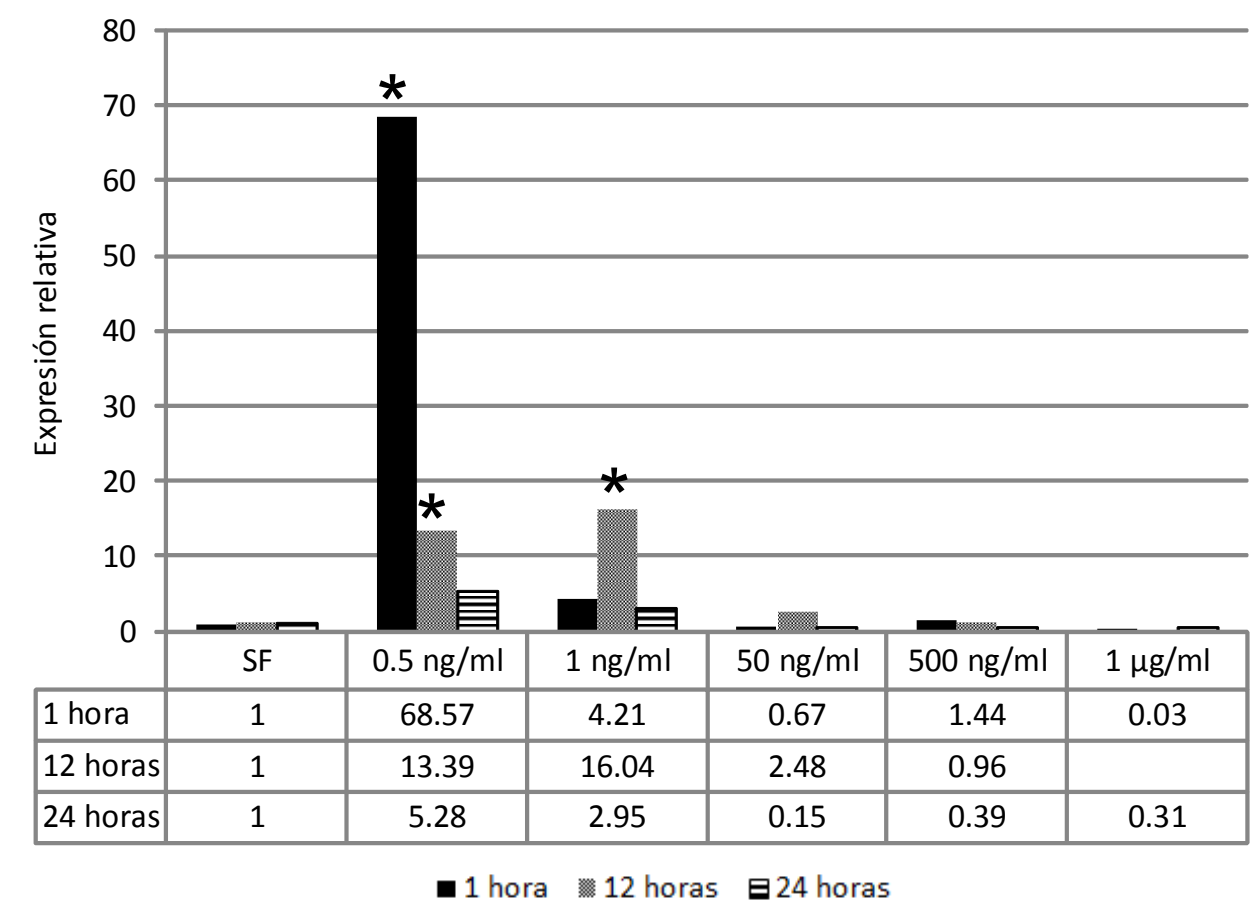

Figura 5. Expresión relativa de ARNm de TNF- $\alpha$ según la concentración del extracto de macroquistes de $S$. aucheniae y el tiempo de incubación $(*=\mathrm{p}<0.05)$

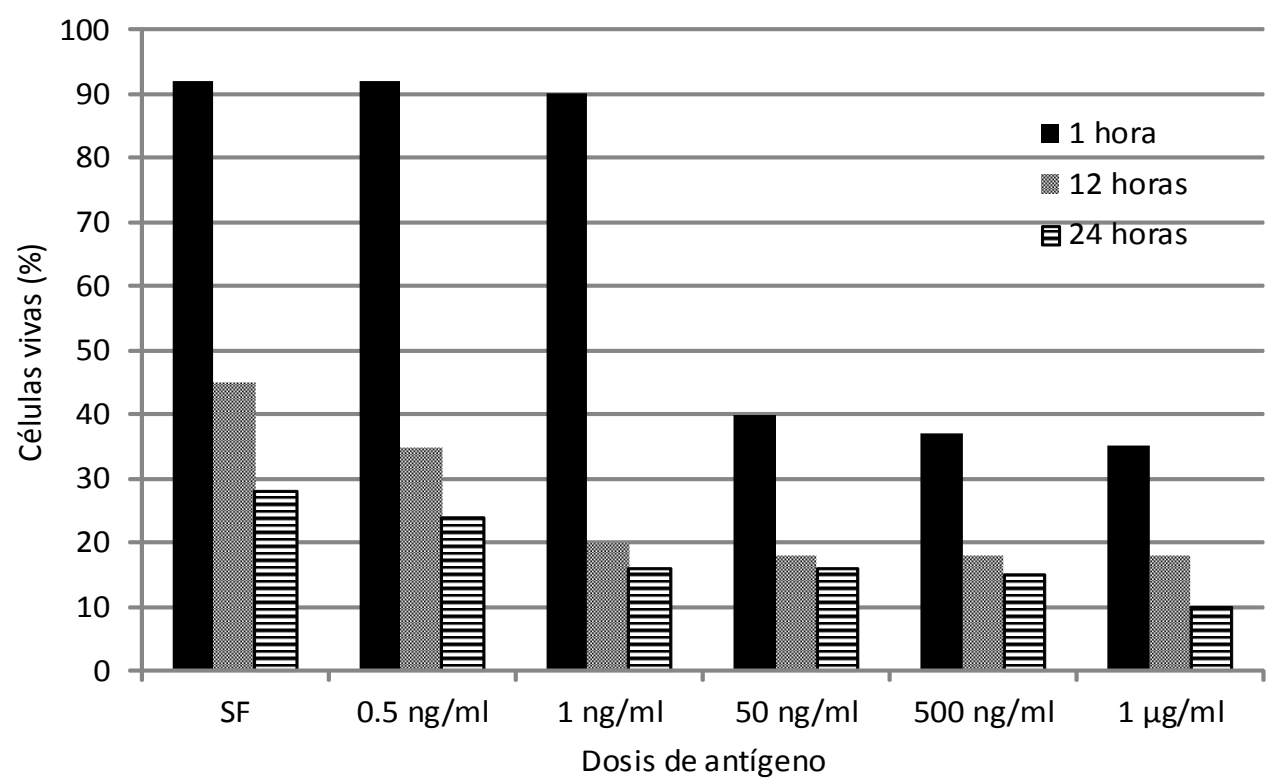

Figura 6. Porcentaje de células vivas postratamiento con antígenos completos de Sarcocystis aucheniae según recuento en la cámara de Neubauer 
centración del antígeno, se encontró que a mayor tiempo de exposición se obtuvo mayor producción de IL-1 $\beta$. Asimismo, se evidencia que a mayor concentración antigénica, menor es la expresión de ARNm de IL- $1 \alpha$, aunque superiores a las células no tratadas después de las 12 horas de exposición.

Los resultados para TNF- $\alpha$ indican un patrón de expresión similar a lo observado para IL-1 $\alpha$, encontrándose que los máximos niveles de expresión se ubican en el tratamiento de dosis mínima $(0.5 \mathrm{ng} / \mathrm{ml})$ y en el periodo de $1 \mathrm{~h}$ de incubación (Fig. 5), donde la expresión llega hasta 68.4 veces lo expresado por el calibrador de una hora. Los niveles descendieron conforme se aumentó la dosis antigénica, siendo significativa aún a las 12 horas de exposición en baja dosis $(\mathrm{p}<0.05)$, pero llegando a niveles por debajo del calibrador en la dosis de $1000 \mathrm{ng} / \mathrm{ml}$.

Los niveles de expresión relativa mostraron diferencia significativa entre grupos $(\mathrm{p}<0.05)$. Los coeficientes de correlación fueron de $-0.33,-0.58$ y de -0.50 a 1,12 y $24 \mathrm{~h}$ de incubación. La correlación negativa entre la concentración antigénica empleada y la expresión de ARNm implica que a mayor dosis de antígeno se produce una menor expresión de ARNm.

\section{Viabilidad Celular}

La viabilidad de las células vivas postratamiento con antígenos completos de Sarcocystis aucheniae se muestra en la Fig. 6. En general, la supervivencia de las células es mayor cuanto menor es la concentración de antígeno. En el caso de $1 \mathrm{~h}$ de incubación, se observa una buena supervivencia $(90 \%)$ hasta $1 \mathrm{ng} / \mathrm{ml}$, determinándose una menor supervivencia de células (40\%) a partir de la concentración de $50 \mathrm{ng} / \mathrm{ml}$, en tanto que en el caso de las $12 \mathrm{~h}$ de incubación, la supervivencia tiende a equilibrarse a partir de la dosis de $1 \mathrm{ng} / \mathrm{ml}$.
En el caso de las $24 \mathrm{~h}$ de incubación, las diferencias en el porcentaje de supervivencia se acortan entre los tratamientos y el control. El porcentaje de supervivencia llega a $10 \%$ con la concentración más alta de antígeno y a $28 \%$ en el tratamiento control.

\section{Discusión}

Los linfocitos circulantes de alpacas han mostrado una expresión de diversos genes de citocinas pro-inflamatorias cuando fueron estimulados por el extracto completo de $S$. aucheniae a diversos tiempos de exposición; esto indica que los leucocitos son estimulados por diferentes moléculas que inducen las transducciones de señales que desencadenen la expresión de las citocinas. Las alpacas utilizadas fueron negativas en la prueba de ELISA para detectar anticuerpos contra $S$. auchenia, pero fueron criadas en un rebaño con animales positivos, según hallazgos en la necropsia y en serología, lo que indicaría que han sido expuestos naturalmente al parásito en alguna etapa de su vida, y podría haber algunas células sensibilizadas en los linfocitos tratados, los cuales no afectarían los resultados obtenidos, ya que solo se está estudiando las citosinas proinflamatorias y no una respuesta inmune adaptativa.

En este estudio se utilizaron leucocitos circulantes en la sangre, lo que constituye una mezcla de células blancas como linfocitos, monocitos, neutrófilos, basófilos, eosinófilos $\mathrm{y}$, en menor proporción, macrófagos, permitiendo que muchos de ellos reconozcan las moléculas que estimulan la producción TNF- $\alpha$ e interleucinas (Dinarello, 2002). En los tejidos in vivo se ha demostrado que los macrófagos son los mayormente estimulados por moléculas extrañas para inducir la liberación y expresión de citocinas pro-inflamatorias (Gery y Waksman, 1972); sin embargo, en la concentración de leucocitos in vitro, otras células como monocitos, neutrófilos y otros fagocitos, además de macrófagos, pueden 
procesar los potenciales antígenos del extracto de $S$. aucheniae e inducir a la expresión de estas citocinas (Mosser et al., 1998).

IL- $1 \alpha$ es producida por fagocitos mononucleares y linfocitos activados e inducidos por sustancias endotóxicas y antígenos intracelulares parasitarios (Dinarello y Moldawer, 1999), como S. aucheniae. En la cuantificación relativa se observó que los niveles de ARNm de IL-1 $\alpha$ generados en una hora eran detectables y comparativamente elevados con respecto al calibrador. En este periodo de tiempo, en situaciones in vivo, se induce y produce la cantidad de interleucina necesaria para su detección, llegando a un pico máximo a las tres horas (Lledó et al., 1994). En los niveles de expresión a las 12 y $24 \mathrm{~h}$ se observa una curva similar al de una hora, pero sin que se genere una intensidad similar en los niveles de expresión, probablemente debido a que los leucocitos, por ser células terminales no mitóticas, envejecen y presentan muerte natural en el cultivo; siendo esto corroborado por el grupo control.

Por otro lado, la disminución en la producción de los ARNm de la IL-1 $\alpha$, podría deberse a la citotoxicidad producida por los antígenos, generando muerte celular en poco tiempo de cultivados (Solíz, 1997). Otro mecanismo de disminución de expresión es la saturación de receptores específicos del 50\% con una concentración proteica de $400 \mu \mathrm{g}$ de ligando específico; además que la afinidad de inductor (antígeno procesado) hacia el receptor específico para la producción de esta interleucuina disminuye con el paso del tiempo (Lledó et al., 1994).

La IL- $\beta$ mostró incremento mayor a la concentración de $1 \mathrm{ng} / \mathrm{ml}$ a las $24 \mathrm{~h}$, evidenciando una expresión después de las IL- $1 \alpha$ y TNF- $\alpha$. La IL- $1 \beta$ es una proteína proinflamatoria, que estimula su propia síntesis, así como de TNF- $\alpha$ y de otras proteínas asociadas con la inflamación y las enfermedades autoinmunes (Dinarello, 2002), de allí que es necesaria su presencia en el medio para autoestimularse y aumentar la expresión de este gen. A pesar de la muerte de un gran número de leucocitos al final del experimento $(24 \mathrm{~h})$ o por la capacidad citotóxica del extracto de $S$. aucheniae, se observa una expresión mayor en relación al control, que indicaría que los leucocitos viables están produciendo esta interleucina, aunque a niveles muy bajos.

La IL-1 $\beta$ está asociada a la proliferación, diferenciación y apoptosis celular (Hazuda et al., 1988). La expresión de esta interleucina en el último periodo del experimento, cuando hay una alta muerte celular, puede estar asociada a apoptosis de estas células en cultivo. Se ha demostrado también que la IL-1 $\beta$ promueve la producción de GMCSF en linfocitos T cd4 + y en linfocitos $T \gamma \delta$ (Lukens et al., 2012), y estos se encuentran en grandes cantidades en la sangre de las alpacas, pudiendo ser un mecanismo de señalización secuencial en la regulación de expresión de citocinas proinflamatorias en esta especie.

Se ha demostrado que la vida media de los isómeros de IL-1 son muy diferentes, siendo la vida media intracelular de IL- $1 \alpha$ de 15 h y de la IL-1 $\beta$ de 2.5 h (Hazuda et al., 1988), lo cual también influiría en la persistencia de la estimulación en los periodos de tratamiento. Esta discrepancia en la vida media es un reflejo de la diferente cinética con la que la IL- $1 \alpha$ y IL- $1 \beta$ son secretadas. IL- $1 \beta$ se libera continuamente a partir de $2 \mathrm{~h}$ de la síntesis, mientras que la secreción de IL-1 $\alpha$ se retrasa por $10 \mathrm{~h}$ (Hazuda et al., 1988). Es por esto que se muestra el patrón ascendente en la IL-1 $\beta$; es decir, se muestra un mayor nivel de expresión conforme se incrementan los periodos de incubación; mientras que en IL-1 $\alpha$ se muestra una mayor expresión en $1 \mathrm{~h}$ de incubación y disminuye según se incrementa el periodo de incubación.

Se ha demostrado, además, que TNF- $\alpha$ expresa altos niveles desde las primeras horas de infección y actúa sinérgicamente con IL-1 $\alpha$ (Vogel et al., 1987). Al emplearse la técnica de cuantificación relativa se pudo 
observar que sigue un patrón similar a IL- $1 \alpha$, lo cual es evidente ya que TNF- $\alpha$ induce la síntesis de IL-1 (Tracey, 1994).

Las interleucinas $1 \alpha$ y TNF- $\alpha$ presentaron patrones similares de respuesta, mostrando una curva ascendente para las concentraciones 0.5 y $1 \mathrm{ng} / \mathrm{ml}$ de antígeno y descendente para el resto. Esto demuestra que el extracto de macroquistes de $S$. aucheniae genera una respuesta inmune al ser inoculado en leucocitos de alpaca, evidenciado por cuantificación relativa de los productos de ARNm de los tratamientos. Esta curva se produce probablemente en respuesta al aumento de carga antigénica sobre los leucocitos; es decir, que estas células generan una respuesta inflamatoria de fase aguda, porque actúan activamente como agentes pro-inflamatorios (Tizard, 2002). Esta similitud de respuesta responde a la característica de TNF- $\alpha$ que activa macrófagos para incrementar su propia síntesis y la de IL-1 (Tizard, 2002). La respuesta de estas citocinas por el antígeno parasitario protozoo intracelular obligatorio (Tender, 1995) se encuentra relacionado, ya que TNF- $\alpha$ promueve la respuesta celular inmune contra la invasión de patógenos intracelulares (Steven et al., 2002).

La interleucina IL-6 no se llegó a evidenciar mediante RT-PCR tiempo real. La técnica fue comprobada como válida mediante controles positivos de enterocitos de alpaca, lo cual indica su escasa participación como inductor de la fase aguda de la inflamación donde participan los leucocitos de alpacas. Heinrich et al. (2003) indican que la IL-6 tiene funciones duales induciendo una respuesta pro-inflamatoria y otra antiinflamatoria regulando la expresión de otras citocinas proinflamatorias; además de inhibir y ser antagonista regulador de la síntesis de IL-1, TNF- $\alpha$ y otras citocinas pro-inflamatorias mayores (Santiago, 1995; Opal y De Palo, 2000). Por otro lado, induce la síntesis de glucocorticoides (Ruzek et al., 1997), hormonas con función antiinflamatoria inespecífica.
La falta de evidencia también pudo deberse al poco tiempo empleado, ya que su función antiinflamatoria in vivo requiere de mayor tiempo para expresarse.

\section{Conclusiones}

- Los leucocitos de alpaca expuestos a extractos de macroquistes de Sarcocystis aucheniae a dosis entre 0.5 a $1000 \mathrm{ng} / \mathrm{ml}$ expresan citocinas proinflamatorias como IL- $1 \alpha$, IL- $\beta$ y TNF- $\alpha$.

- La mayor expresión de IL- $1 \alpha$ y TNF- $\alpha$ en leucocitos estimulados por extracto de macroquiste de $S$. aucheniae se puede detectar a una hora de incubación, mientras que la IL-1 $\beta$ se detecta mejor a las 24 horas.

- El extracto de macroquiste de $S$. aucheniae a altas concentraciones es tóxico para los leucocitos de alpaca.

\section{Agradecimiento}

Los autores agradecen la colaboración financiera del FINCyT-PIBAP 2008 para el desarrollo de esta investigación.

\section{Literatura Citada}

1. Castro E, Sam R, López T, Gonzales A, Silva M. 2004. Evaluación de la edad como factor de riesgo de seropositividad a Sarcocystis sp en alpacas. Rev Inv Vet Perú 15: 83-86.

2. Choque J, Chávez A, Pacheco A, Leyva V, Panez S, Ticona D. 2007. Frecuencia de Sarcocystis sp en perros pastores de asociaciones alpaqueras de Maranganí, Cusco. Rev Inv Vet Perú 18: 84-88.

3. Darling D, Morgan S. 1993. Cultivo de células animales. $18^{\circ}$ ed. España: Ed Acribia. 159 p. 
4. Dinarello C, Moldawer L. 1999. Proinflammatory and anti-inflammatory cytokines in rheumatoid arthritis. A primer for clinicians. USA: Amgen. $282 \mathrm{p}$.

5. Dinarello CA. 2002. The IL-1 family and inflammatory diseases. Clin Exp Rheumatol 20: S1-S13.

6. Gery I, Waksman BH. 1972. Potentiation of the $\mathrm{T}$ lymphocyte response to mitogens. II. The cellular source of potentiating mediator(s). J Exp Med 136: 143-155.

7. Hazuda D, Lee JC, Young PR. 1988. The kinetics of interleukin 1 secretion from activated monocytes: differences between interleukin- $1 \alpha$ and interleukin13. J Biol Chem 263: 8473-8479.

8. Heinrich PC, Behrmann I, Haan S, Hermanns HM, Müller-Newen G, Schaper F. 2003. Principles of interleukin-6-type cytokine signalling and its regulation. Biochem J 374: 1-20. doi: 10.1042/BJ20030407

9. La Perle KM, Silverio F, Anderson DE, Blomme EA. 1999. Dalmeni desease in an alpaca (Lama pacos): Sarcocystosis, eosinophilic, myositis and abortion. J Comp Pathol 121: 287-293. doi: $10.1053 /$ jcpa. 1999.0321

10. Leguía G. 1991. The epidemiology and economic impact of llama parasites. Parasitol Today 7: 54-56. doi: 10.1016/ 0169-4758(91)90190-Y

11. Livak KJ, Schmittgen TD. 2001. Analysis of relative gene expression data using real-time quantitative PCR and the 2(-Delta Delta $\mathrm{C}(\mathrm{T})$ ) method. Methods 25: 402-408. doi: 10.1006/meth. 2001.1262

12. Lledó A, Gau C, Borreil J. 1994. Receptores de interleucina-1 en el sistema nervioso central: estudio de regulación en relación con el eje hipotálamohipófisis-adrenal y en un modelo experimental de esclerosis múltiple. Tesis Doctoral. Madrid: Instituto Cajal - Consejo Superior de Investigaciones Científicas. $155 \mathrm{p}$.
13. Lukens J, Barr M, Chaplin D, Chi H, Kanneganti D. 2012. Inflammasomederived IL-1â regulates the production of GM-CSF by CD4+T cells and $\gamma \delta \mathrm{T}$ cells. J Immunol 188: 3107-3115. doi: 10.4049/jimmunol.1103308

14. Moro M. 1987. Enfermedades infecciosas de las alpacas. Rev Camélidos Sudam 4: 7-31.

15. Mosser B, Loetscher M, Piali L, Loetscher $P$. 1998. Lymphocyte responses to chemokines. Int Rev Immunol 16:323-344.

16. Odbileg R, Konnai S, Usui T, Ohashi K, Onuma M. 2005. Quantification of llama inflammatory cytokine mRNAs by Real-Time RT-PCR. J Vet Med Sci 67: 195-198. doi: 10.1292/jvms.67.195

17. Opal S, DePalo V. 2000. Impact of basic research on tomorrow's medicine. Anti-inflammatory cytokines. Chest 117 : 1162-1172.

18. Patil A, Hughes A, Zhang G. 2004. Rapid evolution and diversification of mammalian á-defensins as revealed by comparative analysis of rodent and primate genes. Physiol Genomics 20: 1-11. doi: 10.1152/physiolgenomics.00150.2004

19. Pfaffl $M W$. 2001. A new mathematical model for relative quantification in realtime RT-PCR. Nucleic Acids Res 29(9): e45.

20. Rebrikov DV, Trofimov D. 2006. RealTime PCR: A review of approaches to data analysis. Appl Biochem Microbiol 42:455-463.

21. Ruzek M, Miller A, Opal S. 1997. Characterization of early cytokine responses in a interleukin-6-dependent pathway of endogenous glococorticoid induction during murine cytomegalovirus infection. J Exp Med 183: 1183-1192.

22. Sam R, Mansilla I, Morales C, Ramírez A. 1998. Efecto tóxico de macroquistes de Sarcocystis aucheniae en ratones, cobayos y conejos. Rev Inv Pec IVITA 9(2): 11-18.

23. Santiago E. 1995. Estudio del efecto de la interleucina 6 (IL-6) sobre la síntesis de colágeno, y de sus mecanismos 
de acción, en cultivo de lipocitos. Tesis doctoral. Madrid: Universidad Complutense de Madrid. $189 \mathrm{p}$.

24. Solíz J. 1997. Mecanismos de citotoxicidad del factor de necrosis tumoral-á en las líneas celulares L929 y HEPG2. Tesis doctoral. Madrid: Universidad Complutense de Madrid. 194 p.

25. Steven AC, Weinberg WC, Yuspa SH. 2002. Mt CLIC/CLIC 4, an organellular chloride channel protein, is increased by DNA damage and participates in the apoptotic response to p53. Mol Cell Biol 22:3610-3620.

26. Tender AM. 1995. Current research on Sarcocystis species of domestic animals. Int J Parasitol 25: 1311-1330. doi: 10.1016/0020-7519(95)00068-D
27. Tizard I. 2002. Inmunología veterinaria. $4^{\circ}$ ed. España: Interamericana McGraw-Hill. 517 p.

28. Tracey K. 1994. Tumor necrosis factor-alpha. En: Thomson A. The cytokine handbook. San Diego, USA: Academic Press. p 289-300.

29. Uggla A, Buxton D. 1990. Immune responses against Toxoplasma and Sarcocystis infections in ruminants: diagnosis and prospects for vaccination. Rev Sci Tech 9: 441-462.

30. Vogel S, Douches $S$, Kaufman E, Neta $R$. 1987. Induction of colony stimulating factor in vivo by recombinant interleukin 1 alpha and recombinant tumor necrosis factor alpha 1. J Immunol 138: 2143 2148 . 